\title{
Publisher Correction: How we created neuromorphic engineering
}

Carver Mead

Correction to: Nature Electronics https://doi.org/10.1038/s41928-020-0448-2, published online 21 July 2020.

In the version of this Reverse Engineering article originally published, the caption for Fig. 1 was missing the image credit to Rodney Douglas; the article has now been updated.

Published online: 24 July 2020

https://doi.org/10.1038/s41928-020-0462-4

(c) Springer Nature Limited 2020 